\title{
Editorial
}

\section{Heat Treatment of Steels}

\author{
Andrea Di Schino ${ }^{1, *(\mathbb{D})}$ and Claudio Testani ${ }^{2} \mathbb{B}$
}

1 Dipartimento di Ingegneria, Università degli Studi di Perugia, Via G. Duranti 93, 06125 Perugia, Italy

2 CALEF-ENEA CR Casaccia, Via Anguillarese 301, Santa Maria di Galeria, 00123 Rome, Italy;

claudio.testani@consorziocalef.it

* Correspondence: andrea.dischino@unipg.it

Citation: Di Schino, A.; Testani, C. Heat Treatment of Steels. Metals 2021, 11, 1168. https://doi.org/10.3390/ met11081168

Received: 20 July 2021

Accepted: 21 July 2021

Published: 23 July 2021

Publisher's Note: MDPI stays neutral with regard to jurisdictional claims in published maps and institutional affiliations.

Copyright: (C) 2021 by the authors. Licensee MDPI, Basel, Switzerland. This article is an open access article distributed under the terms and conditions of the Creative Commons Attribution (CC BY) license (https:// creativecommons.org/licenses/by/ $4.0 /)$.

\section{Introduction and Scope}

Steels represent an interesting family of materials, both from a scientific and commercial point of view, considering the many innovative applications they can be used for [1]. It is therefore essential to understand the relations between properties and microstructure and how to drive them via a specific process. Despite their wide use as a consolidated material, many research fields remain active in finding new applications for steels. Particularly within this framework, the role of heat treatments in obtaining even complex microstructures is still a relatively open matter, thanks to the design of these innovative heat treatments [2-6].

The Special Issue scope embraces interdisciplinary work covering physical metallurgy and processes, reporting on experimental and theoretical progress concerning microstructural evolution during the heat treatments of steels.

\section{Contributions}

The volume collects contributions from academic and industrial researchers with stimulating new ideas and original results. The present volume consists of 14 research papers and two review papers. Hoja et al. [7] report on deep nitriding as a tool to obtain a nitriding hardness depth beyond $0.6 \mathrm{~mm}$. They show how long-nitriding processes, which are necessary to reach high-nitriding hardness depths, mostly have a negative influence on the hardness and strength of the nitrided layer of steel, as well as on the bulk material. It is shown that thick and compact compound layers have the potential for a high-flank load capacity of gears. The investigations focus on the simultaneous formation of a highnitriding depth and a thick and compact compound layer. Beside the preservation of its strength, a challenge is to control the porosity of the compound layer, which should be as low as possible. The investigations were carried out using the common nitriding and heat-treatable mild steel, $31 \mathrm{CrMoV} 9$, which is often used for gear applications. The article gives an insight on the development of multistage nitriding processes, studied by shortand long-term experiments, which aim for a specific compound-layer build-up with low porosity and the high strength of the nitride layer and core material.

Di Schino et al. [8] report on the corrosion behavior and the mechanical properties of a Q235 plate clad by AISI 316 stainless steel. The reported cladding process is performed by the submerged-arc welding overlay process. Due to element diffusion $(\mathrm{Fe}, \mathrm{Cr}, \mathrm{Ni}$, and $\mathrm{Mn}$ ), a $1.5 \mathrm{~mm}$ wide diffusion layer is formed between the stainless steel and carbon steel interface of the cladded plate affecting corrosion resistance. Pitting resistance and intergranular corrosion are both evaluated.

Soffritti et al. [9] report on the influence of vacuum heat treatments on the microstructure and mechanical properties of M35 high-speed steel. Their study investigates the influence of vacuum heat treatments, at different pressures of quenching gas, on the microstructure and mechanical properties of taps made of M35 high-speed steel.

Hu et al. [10] report on an analytical model for comparing and selecting a creep constitutive equation for a stress-relief investigation into ferritic welded structure during heat 
treatment. A one-dimensional analytical model is proposed to help select the creep constitutive equation and predict the temperature of heat treatment in a ferritic welded structure, while neglecting the impact of structural constraint and deformation compatibility. The analytical solutions were compared with simulation results, which were validated with experimental measurements in a ferritic welded rotor. The residual stresses from welding and post-welding heat treatment on the inner and outer cylindrical surfaces were measured with the hole-drilling method for validation.

Di Schino et al. [11] describe the heat treatment effect on microstructure evolution in $7 \% \mathrm{Cr}$ steel for forging. In their paper, different heat treatments are considered and their effect on a $7 \% \mathrm{Cr}$ steel for forging is reported. Results show that, following the high-intrinsic steel hardenability, significant differences were not found in comparison to the cooling-step treatment, although prior austenite grain size was significantly different. Moreover, retained austenite content was lower in double-tempered specimens after heat treatments at higher temperatures.

Franceschi et al. [12] describe the effect of inter-critical annealing and austempering on the microstructure and mechanical properties of high-silicon manganese steel. In their study, they report on the achievement of a multiphase ferritic-martensitic microstructure characterized by a hardness of $426 \mathrm{HV}$ and a tensile strength of $1650 \mathrm{MPa}$, together with an elongation of $4.5 \%$. They compare their results with those values obtained with annealing and Q\&T treatments.

Jung et al. [13] report on the relationship between microstructures and ductility parameters, including the reduction in area, elongation to failure, occurrence of delamination, and the number of turns until failure in torsion in hypereutectoid pearlitic steel wires.

Kaltzakorta et al. [14] describe the results obtained for a $0.66 \mathrm{C} 11.4 \mathrm{Mn} 9.9 \mathrm{Al}$ duplex austenitic low-density steel after applying a set of isothermal treatments at different combinations of time and temperature, aiming to promote kappa-carbide precipitation and improve the mechanical properties obtained with a water-quenching treatment. The effects of the different isothermal treatments on the microstructure and mechanical properties of the steel were analyzed.

Shimotomai [15] reports on advanced, tempered, martensitic steels. He shows how their mechanical strength is characterized by fine sub-grain structures with a high density of free dislocations and metallic carbides and/or nitrides. This paper is a preliminary experimental survey of the hydrogen absorption and hydrogen embrittlement of a tempered martensitic steel with $\varepsilon$-carbide precipitates. Shimotomai suggests that the proper use of carbides in steels can promote a high resistance to hydrogen embrittlement.

Liu et al. [16] report on the precipitation criterion for inhibiting austenite grain coarsening during carburization of $20 \mathrm{Cr}$ gear steels containing Al. In their paper, the quantitative influence of $\mathrm{Al}$ and $\mathrm{N}$ on grain size after carburization is studied through experiments based on $20 \mathrm{Cr}$ steel. According to the grain-structure features and kinetic theory, the abnormal grain growth is demonstrated as the mode of austenite grain coarsening in carburization.

Hernandez-Duran et al. [17] report on the effect of different annealing strategies on the microstructure development and the mechanical response of bainitic steels. Their study focuses on the effect of non-conventional annealing strategies on the microstructure and mechanical properties of austempered steels. Multistep thermo-cycling and ultrafast heating annealing were carried out and compared with the outcome obtained from a conventionally annealed 0.3C-2Mn-1.5Si steel.

Acosta-González et al. [18] contribute to the volume with a review concerning heattransfer phenomena when quenching metals from high temperatures. The purpose of their work is to acquaint the field engineer, the graduate student, or any research professional with the current knowledge on heat-transfer phenomena during metal quenching and the methods used for their interpretation and application.

Jiang et al. [19] report on automotive steels with ultra-high strength and low alloy content under different heating and cooling processes. It was shown that those processes 
exhibited great influence on the performance of the investigated steels due to the different auto-tempering effects.

Carpio et al. [20] report on the effect of Q\&P heat treatment on a new family of steels for the automotive industry.

Acknowledgments: As Guest Editors, we would like to especially thank Kinsee Guo, Assistant Editor, for his support and his active role in the publication. We are also grateful to the entire staff of Metals Editorial Office for this precious collaboration. Last but not least, we express our gratitude to all the contributing authors and reviewers: without your excellent work it would not have been possible to accomplish this Special Issue that we hope will be a piece of interesting reading and reference literature.

Conflicts of Interest: The authors declare no conflict of interest.

\section{References}

1. Di Schino, A. Manufacturing and application of stainless steels. Metals 2020, 10, 327-329. [CrossRef]

2. Di Schino, A.; Alleva, L.; Guagnelli, M. Microstructure evolution during quenching and tempering of martensite in a medium C steel. Mater. Sci. Forum 2012, 715-716, 860-865. [CrossRef]

3. Di Schino, A.; Di Nunzio, P.E. Metallurgical aspects related to contact fatigue phenomena in steels for back up rolling. Acta Metall. Slovaca 2017, 23, 62-71. [CrossRef]

4. Di Schino, A. Analysis of phase transformation in high strength low alloyed steels. Metalurgija 2017, 56, 349-352.

5. Di Schino, A.; Di Nunzio, P.E.; Turconi, G.L. Microstructure evolution during tempering of martensite in a medium C steel. Mater. Sci. Forum 2007, 558-559, 1435-1441. [CrossRef]

6. Mancini, S.; Langellotto, L.; Di Nunzio, P.E.; Zitelli, C.; Di Schino, A. Defect reduction and quality optimization by modeling plastic deformation and metallurgical evolution in ferritic stainless steels. Metals 2020, 10, 186. [CrossRef]

7. Hoja, S.; Steinbacher, M.; Zoch, H.W. Compound layer design for deep nitride gearings. Metals 2020, 10, 455. [CrossRef]

8. Di Schino, A.; Testani, C. Corrosion behavior and mechanical properties of AISI 316 stainless steel clad Q235 plate. Metals 2020, 10, 552. [CrossRef]

9. Soffritti, C.; Fortini, A.; Sola, R.; Fabbri, E.; Merlin, M.; Garagnani, G.L. Influence of vacuum heat treatments on microstructure and mechanical properties of M35 high speed steel. Metals 2020, 10, 643. [CrossRef]

10. Hu, M.; Li, K.; Li, S.; Cai, Z.; Pan, J. Analytical model to compare and select creep constitutive equation for stress relief investigation during heat treatment in ferritic welded structure. Metals 2020, 10, 688. [CrossRef]

11. Di Schino, A.; Gaggiotti, M.; Testani, C. Heat treatment effect on microstructure evolution in $7 \%$ Cr steel for forging. Metals 2020, 10, 808. [CrossRef]

12. Franceschi, M.; Pezzato, L.; Gennari, C.; Fabrizi, A.; Polyakova, M.; Konstantinov, D.; Brunelli, K.; Dabalà, M. Effect of intercritical annealing and austempering on the microstructure and mechanical properties of high silicon manganese steel. Metals 2020, 10, 1448. [CrossRef]

13. Jung, J.Y.; An, K.S.; Park, P.Y.; Nam, W.Y. Correlation between Microstructures and Ductility Parameters of Cold Drawn HyperEutectoid Steel wires with different drawing strains and post-deformation annealing conditions. Metals 2021, 11, 178. [CrossRef]

14. Kaltzakorta, I.; Gutierrez, T.; Elvira, R.; Jimbert, P.; Guraya, T. Evolution of Microstructure during Isothermal Treatments of a Duplex-Austenitic 0.66C11.4Mn.9.9Al Low-Density Forging Steel and Effect on the Mechanical Properties. Metals 2021, 11, 214. [CrossRef]

15. Shimotomai, M. Heuristic Design of advanced martensitic steels that are highly resistant to hydrogen embrittlement by $\varepsilon$-carbide. Metals 2021, 11, 370. [CrossRef]

16. Liu, H.; Dong, Y.; Zheng, H.; Liu, X.; Lan, P.; Tang, H.; Zhang, J. Precipitation criterion for inhibiting austenite grain coarsening during carburization of Al-containing 20Cr gear steels. Metals 2021, 11, 504. [CrossRef]

17. Hernandez-Duran, E.; Corallo, L.; Ros-Yanez, T.; Castro-Cerda, F.; Petrov, R.H. The effect of different annealing strategies on the microstructure development and the mechanical response of bainitic steels. Metals 2021, 11, 1041. [CrossRef]

18. Acosta-González, F.A.; Barrena-Rodriguez, M.; Tellez-Rosas, M.M. A review of the boiling curve with reference to steel quenching. Metals 2021, 11, 974.

19. Jiang, H.; He, Y.; Lin, L.; Liu, R.; Zhang, Y.; Zheng, W.; Li, L. Microstructures and properties of auto-tempering ultra-high strength automotive steels under different thermo-processing. Metals 2021, 11, 1121. [CrossRef]

20. Carpio, M.; Calvo, J.; Garcia, O.; Pedraza, J.P.; Cabrera, J.M. Heat Treatment Design for a QP Steel: Effect of Partitioning Temperature. Metals 2021, 11, 1136. [CrossRef] 